VORTEX MOTION IN COMPRESSIBLE FLUIDS. [NoV.
[N

the facts recently added to our knowledge of the triangle, and which indicutes many other's. A similar treatment of the quartic would follow. It is hardly an objection to say that the reader is not supposed to know about covariants, for here is as good a way as any to introduce them to him. The plan thus briefly sketched has, of course, no pretension to novelty; its claim to consideration here lies in its ability to classify and connect much of that matter of the book which is not already connected and classified by the methods of projection and reciprocation.

I have dwelt enough on defects in the author's programme. But in its handling so much power is displayed that one hopes he will set his hand to the plough again, and deal largely with some part of the present outlook as stated in Klein's "Vergleichende Betrachtungen" (BuLLE'rs, July, 1893); throwing exumination schedules, if they interfere, to the four winds of heaven.

Frank Morley.

West Falmouth, Mass., August, 1893.

\title{
PAPERS OF MR. CHARLES CHREE ON VOR'TICES IN A COMPRESSIBLE AND ROTATING FLUID.
}

J'He recent appointment of Mr. Charles Chree, M.A., of King's College, Cambridge, Eng., to be Superintendent of Kew Observatory as the successor of the late Mr. IVhipple, leads us to hope that the study of the mathematical and physical problems whose solution is so important to the progress of meteorology will now receive a great stimulus in England. Mr. Chree has hitherto been known to us mostly through his excellent works in pure mathematics as applied to the subjects of elasticity and of vortex motion: his papers on vortex motion are probably but little known to the mathematical physicists of America, and with the anthor's help we are able to present the following account of his memoirs, which will be of interest to meteorologists in so far as the assumptions which underlie his mathematical solutions harmonize with the conditions that prevail in the atmosphere. On this latter point $\mathrm{Mr}$. Chree very properly and modestly says :

"I should be sorry if any one supposed I profess to have actually solved the exact problems presented by nature. The lay reader is so much at the mercy of the mathematician that I think the latter is taking a most unfair advantage of his position if he avoid taking a reasonable care to prevent the 
general public from regarding his hypothetical problems as actual facts."

This most admirable statement of a fundamental principle of scientific integrity is followed by a paragraph repeating in detail the cautions that are interspersed throughout Mr. Chree's papers as to the practical application of his work to the earth's atmosphere:

"Vortices on the eurth do not extend to infinity: their cross-section is often not small compared to their distance apart ; their diameter is often not very small compared to the earth's radius; they are often not approximately circular in section ; there are vertical currents, and the horizontal velocity is not the same either in magnitude or direction at all points in the same vertical line; air, moist or dry, is not wholly destitute of viscosity, etc., etc. ; there are thus enormous obvious differences between the simple mathematical problems of my papers and the actual state of matters on the earth; and if there is any resemblance between the results in the papers and actualities, it may quite as likely be a pure accident as not."

There are so many kinds of vortex motion present in the atmosphere, from the minute streams of hot air that rise from every point of the landscape when bathed in sunshine, or the columns of smoke that ascend from every chimney, or the rolling front of a horizontal flow of air, up to the cumulus cloud, the waterspout, the tornado, the hurricane, and even the general circulation of the atmosphere, and these present such a great variety of characteristic differences, that it will not be altogether a pure accident if the mathematician in solving some simple problem has paved the way for a better understanding of the complex phenomena that the meteorologist has to study.

Mr. Ohree's papers deal with vortex motion in compressible fluids. The exact mathematical problems he has treated are those of infinite straight vortices or of circular ring vortices. The former case includes a straight vortex perpendicular to an infinite plane which limits it in one direction. In his first paper, "On vortices" (Proc. Edinb. Math. Society, vol. v., session 1886-87), it is shown that if there be two parallel thin straight vortices in a compressible fluid limited by infinite planes, then their distance apart, if their density alters, does not remain constant-as in a liquid-but increases or diminishes according as the sum of their cross-sections is increasing or diminishing. The path of one such vortex relative to the other is an equiangular spiral. On pages 58,59 are pointed out certain conclusions that would hold in the case of cyclones on the earth if the conditions sufficiently resembled those of the problem. 
A second paper, "Vortex rings in a compressible fluid" (Proc. Edinb. Math. Soc., vol, vi., pages 59-68), works out the case of a single ring or of a ring and its image in an infinite plane-which might apply to a ring outside a sphere of large radius - the plane of the ring being parallel to the infinite plane. There is no "practical" application in that paper.

Mr. Chree's third paper, "On vortex motion in a rotating fluid" (Proc. Ediub. Math. sSoc., vol. vir., pages 29-41), denls with questions more nearly allied to the actual problems on the earth. 'The fluid is supposed to rotate with uniform angular velocity round an axis. He first solves the case of a vortex and its image in an infinite plane. Then comes the case of a vortex inside, but not at the centre, of a right circular cylinder, the whole system rotating round the cylinder's axis uniformly. 'This requires an image system of course. The conclusions the results would lead to, if applicable to a vortex on the eurth's surface, are pointed out in pages 39-41. Some of them seem to have some resemblance to actual phenomena.

His last published paper, "On equations of vortex motion with special reference to the use of polar co-ordinates" (Proc. Edlinb. Math. Soc., vol. virr., pages 43-64), deals generally with polar co-ordinates, and treats the case of a vortex ring in a rotating fluid, ontside of a sphere, or parallel to an infinite plane. There would appear to be a motion of the ring similar to that of the plane of vibration of a Foucault's pendulum, the angular velocity varving as the sine of the latitude. 'There is, however, a difficulty in satisfying the conditions at the surface of the ring. 'This perhaps night be got rid of by supposing the existence of viscosity in the fluid.

Between the publication of the first and second of the above papers Mr. Chree published in the Messenger of Mathematics, November, 1887, a paper " On vortices in a conılressible fluid," which may be considered as in extension to compressible fluids of Professor J. J. 'Thomson's prize-essay "On the motion of vortex rings ;" it treats of the vibrations and chinges of shape of cylindrical vortices in a compressible fluid.

In the four first-mentioned papers Mr. Chree gives innumerable hints as to motions in the curth's atmosphere, thus showing that he has meteorological problems in his mind, although he disclaims having as yet resolved any questions except those that relate to a simplified ideal atmosphere.

We trust that the strictly meteorological work of Mr. Chree's new position will tempt him to apply modern mathematical analysis to the winds, the clonds, and the storms of the actual atmosphere.

(iteveliani) Abre. 